\title{
Hubungan Pembelajaran Berbasis Masalah Dengan Keterampilan Berpikir Kritis Dan Literasi Lingkungan Siswa
}

\author{
Suhirman \\ Tadris IPA Biologi, Fakultas Tarbiyah dan Keguruan Universitas Islam Negeri Mataram \\ suhirman@uinmataram.ac.id
}

\begin{abstract}
Abstrak. Tujuan penelitian ini adalah untuk mengetahui hubungan pembelajaran berbasis masalah dengan keterampilan berpikir kritis dan literasi lingkungan di Madrasah Aliyah Negeri 2 Lombok Tengah. Populasi dalam penelitian ini adalah siswa Madrasah Aliyah Negeri 2 Lombok Tengah kelas XIIABC. Teknik pengambilan sampel dengan purposive sampling, yang melibatkan jumlah siswa 56 orang. Data dianalisis dengan menggunakan regresi parsial dan regresi ganda. Hasil penelitian secara parsial menunjukkan bahwa: 1) Pembelajaran berbasis masalah berpengaruh positif dan signifikan terhadap literasi lingkungan yang dibuktikan dengan koefisien korelasi perolehan sebesar 0.267 ; 2) Keterampilan berpikir kritis berpengaruh positif dan signifikan terhadap literasi lingkungan yang dibuktikan dengan koefisien korelasi perolehan sebesar $0.311 ; 3$ ) Pembelajaran berbasis masalah berpengaruh positif dan signifikan terhadap keterampilan berpikir kritis siswa yang dibuktikan dengan koefisien korelasi perolehan sebesar 0.429. Sedangkan bersama-sama hasil penelitian ini menunjukkan bahwa pembelajaran berbasis masalah dan keterampilan berpikir kritis siswa berpengaruh positif terhadap literasi lingkungan yang dibuktikan dengan koefisien korelasi perolehan sebesar 0.337. Jadi, hubungan antara X1 dan Y; X2 dan Y; X1 dan X2 bersifat linier positif dan searah, artinya peningkatan perolehan penerapan pembelajaran berbasis masalah dan keterampilan berpikir kritis akan diikuti dengan kemampuan literasi lingkungan siswa.
\end{abstract}

Kata kunci: Pembelajaran Berbasis Masalah; Keterampilan Berpikir Kritis; Literasi Lingkungan

\section{PENDAHULUAN}

Selama beberapa dekade tahun terkahir, perhatian programmer pendidikan terhadap fenomena penghancuran lingkungan semakin tinggi (Karimzadegan \& Meiboudi, 2012). Sekolah/Madrasah sebagai tempat belajar dan mendidik siswa harus dijadikan sebagai wahana untuk menanam dan menyebarkanluaskan budaya pelestarian lingkungan. Konferensi Bangsa-Bangsa tentang Lingkungan Manusia yang diselenggarakan di Stockholm, Swedia pada tahun 1971 merupakan upaya serius tentang perhatian umat manusia terhadap lingkungan hidup. Selanjutnya pada bulan Oktober tahun 1977 diselenggarakan Konferensi Pendidikan Lingkungan di Tibilisi, yang diselenggarakan oleh UNESCO bekerja sama dengan UNEP. Deklarasi Tbilisi yang mengikuti Piagam Beograd menguraikan dokumen yang lebih komprehensif tentang tujuan, sasaran, peran, karakteristik, kerangka kerja dan pedoman pendidikan lingkungan

$$
\text { Pengajaran tentang lingkungan }
$$

harus melatih dan orang yang sadar akan lingkungan dan tanggung jawab mereka dalam melestarikannya. Literasi Lingkungan, yang dianggap sebagai bagian penting dari pendidikan lingkungan, tampaknya telah diabaikan di sekolah-sekolah wilayah Mataram Nusa Tenggara Barat. Seperti negara-negara lain, kondisi lingkungan alam di Mataram Nusa Tenggara Barat semakin hari semkin mengkhawatirkan, seperti masalah sampah, banjir, erosi, pencemaran air, udara dan tanah, erosi merupakan masalah yang hampir tiap tahun menjadi siklus yang belum dapat diatasi secara menyeluruh.

Literasi lingkungan mencakup enam komponen utama, yakni pengetahuan ekologis, sosial-politik, isu-isu lingkungan, keterampilan kognitif dan perilaku yang bertanggung jawab terhadap lingkungan. Literasi lingkungan tidak tercakup lengkap dalam buku teks sains sekolah-sekolah di Mataram. Komponen literasi lingkungan tidak mendapat perhatian yang sama. Beberapa penelitian yang pernah dilakukan yang berkaitan dengan literasi lingkungan adalah di Makedonia dan Turki, dalam kurikulum 
pendidikan sains di kedua negara tersebut, sebagian besar masih berupa pengetahuan, belum mengarah pada keterampilan dan sikap, bahkan rendahnya perilaku yang bertanggung jawab pada lingkungan (Srbinovski et al., 2010).

Hasil penelitian meunjukkan bahwa peserta tidak memiliki pengetahuan lingkungan yang memadai yang berhubungan dengan pendidikan lingkungan, meskipun sikap, kepedulian, dan persepsi mereka terhadap masalah lingkungan relatif tinggi (Saribas, Teksoz, \& Ertepinar, 2014). Sedangkan yang dilaksanakan di negara Iran, komponen yang berkaitan dengan pengetahuan lingkungan mendapat perhatian yang sangat tinggi, sedangkan komponen lain sebagian besar diabaikan di sekolah dasar Iran (Karimzadegan \& Meiboudi, 2012).

Keterampilan yang dibutuhkan untuk menghadapi tantangan abad ke-21 tidak hanya kegiatan mengajar, membaca, menulis, dan berhitung tetapi juga tentang mengembangkan keterampilan berpikir menjadi keterampilan berpikir kritis. Terdapat 4 keterampilan yang dibutuhkan untuk generasi abad ke-21 yang dikenal sebagai 4C, yakni creativity and innovation, critical thinking and problem solving, communication, and collaboration (Astuti et al., 2019; Bedir, 2019). Berpikir kritis, sebagai salah satu keterampilan berpikir utama, dianggap sebagai salah satu keterampilan abad ke-21 yang harus dicakup dalam pendidikan (Aljaafil \& Şahin, 2019). Salah satu keterampilan hidup yang sangat dibutuhkan di era globalisasi adalah keterampilan berpikir kritis (Bustami, Syafruddin, \& Afriani, 2018; Anazifa \& Djukri, 2017; Khasanah, Sajidan, \& Widoretno, 2017).

Dalam kegiatan pembelajaran biologi peningkatan keterampilan berpikir kritis siswa ternyata belum mendapat perhatian serius dari para guru. Keterampilan berpikir kritis adalah keterampilan dasar yang dimiliki oleh siswa untuk beradaptasi dengan tantangan eksternal abad ke-21 (Putra et al., 2018). Keterampilan berpikir kritis merupakan salah satu keterampilan penting dalam memasuki dunia kerja dan dalam menjalani kehidupan, sehingga kualitas hidup manusia dapat menjadi lebih baik.

Setiap jenjang pendidikan mempunyai peran penting dalam meningkatkan keterampilan berpikir kritis siswa, terutama siswa biologi. Tujuan jangka pendek keterampilan berpikir kritis adalah untuk memperkuat pemahaman konseptual siswa terutama pada mata pelajaran Ilmu Pengetahuan Alam (IPA) (Khasanah et al., 2017). Kemampuan berpikir ilmiah dapat dianggap sebagai bagian dari pemikiran kritis (Suciati, Ali, Imaningtyas, Anggraini, \& Dermawan, 2018).

Kegiatan pembelajaran di sekolah belum dapat meningkatkan pemikiran kritis siswa secara optimal (Anazifa \& Djukri, 2017). Diperlukan penggunaan model pembelajaran seperti Problem Based Learning (PBL) (Kurniawan et al., 2019). Tantangan dalam mengajar dan belajar di era teknologi saat ini menjadi sangat kompleks karena perubahan lingkungan yang telah mempengaruhi persepsi peserta didik, ide-ide, dan karakter (Sada, 2019).

Berpikir kritis merupakan kemampuan untuk mengevaluasi atau menilai kredibilitas, validitas dan nilai dari sesuatu (Aljaafil \& Şahin, 2019). Merancang dan mengintervensi pembelajaran secara sistematis untuk menciptakan lingkungan belajar perlu dilakukan dan diteliti efektivitasnya dalam mengembangkan keterampilan berpikir siwa (Tiruneh, De Cock, \& Elen, 2018; Delaney, Pattinson, Mccarthy, \& Beecham, 2017).

Berpikir kritis, menumbuhkan kemandirian. Salah satu metode pengajaran yang inovatif yang dapat diimplementasikan dalam pembelajaran Biologi adalah pembelajaran berbasis masalah (PBM). Kemampuan berpikir peserta didik juga bisa dikembangkan dengan menerapkan model Problem-Based Learning (PBL) (Nuswowati et al., 2017). Indikator rendahnya kualitas pendidikan dapat diperhatikan dari strategi, metode, model dan cara mengajar guru. Secara umum, proses pembelajaran di tingkat sekolah menengah dan atas cenderung menggunakan pembelajaran konvensional seperti ceramah, penugasan, menggunakan buku teks yang lebih didominasi guru dan 
siswa pasif dalam belajar. Belajar tidak diarahkan untuk menemukan masalah dan mendapatkan solusinya, juga tidak diarahkan dengan kehidupan nyata siswa. Kurikulum 2013 memberikan alternatif beberapa strategi pembelajaran untuk guru dan Murid. Guru mestinya lebih kreatif, untuk menumbuhkan keaktifan siswa (Sada, 2019).

Pembelajaran berbasis masalah merupakan model pembelajaran dirancang dalam suatu prosedur pembelajaran yang diawali dengan sebuah masalah spesifik (Witte \& Rogge, 2016; Sadia, 2014). Berpusat pada siswa dan membutuhkan pengetahuan umum sebelumnya. Siswa lebih aktif dalam memperoleh informasi dari berbagai sumber. Pembelajaran berbasis masalah juga mampu mengembangkan proses penalaran, meningkatkan keterampilan belajar mandiri, dan meningkatkan motivasi intrinsik mereka untuk belajar (Aldarmahi, 2016). Sehingga sejak diterapkan pertama kali hingga sekarang ini pembelajaran berbasis masalah menjadi salah satu metode yang mendapat perhatian yang cukup besar di Indonesia terutama dalam dunia pendidikan tingkat menengah dan atas.

\section{METODE}

Populasi dalam penelitian ini adalah jumlah atau kesatuan individu yang memiliki sifat-sifat sama sehingga dapat diberlakukan generalisasi. Dalam penelitian ini yang menjadi populasi adalah siswa MAN 2 Lombok Tengah kelas XII. Teknik pengambilan sampel menggunakan purposive sampling, dengan kriteria: 1) siswa yang terdaftar sebagai kelas XII, 2) menempuh mata pelajaran Biologi Terpadu. Pengumpulan data dalam penelitian ini menggunakan tes berpikir kritis dan tes literasi lingkungan. Pengembangan tes disusun berdasarkan teori yang telah diuraikan sebelumnya. Pernyataan dalam tes bersifat tertutup dengan jawaban pilihan ganda.

Dalam penelitian ini yang menjadi populasi adalah siswa Madrasah Aliyah Negeri Lombok Tengah kelas XIIABC. Teknik pengambilan sampel menggunakan purposive sampling, yang melibatkan jumlah siswa 56 orang dengan kriteria: 1) siswa yang terdaftar sebagai kelas XII, 2) menempuh mata pelajaran Biologi Terpadu. Analisis data yang digunakan adalah regresi parsial dan regresi ganda.

\section{HASIL DAN PEMBAHASAN}

Data hasil penelitian hubungan pembelajaran berbasis masalah dengan keterampilan berpikir kritis dan literasi lingkungan, secara ringkas dapat ditampilkan pada tabel berikut ini.

Tabel 1. Hubungan antara pembelajaran berbasis masalah dengan literasi lingkungan

\begin{tabular}{|l|r|rr|r|r|r|}
\hline Jumlah siswa & $\mathrm{Xl}$ & $\mathrm{Y}$ & & $\mathrm{Xl}^{2}$ & $\mathrm{Y}^{2}$ & $\mathrm{XlY}$ \\
\hline 56 & 5.276 & 5.563 & 538.706 & 596.803 & 565.066 \\
\hline
\end{tabular}

Berdasarkan Tabel 1 di atas diperoleh bahwa nilai $\Sigma \mathrm{X} 1$ adalah $5.276 ; \Sigma \mathrm{Y}=5.563$; $\Sigma X 1^{2}=538.706 ; \Sigma Y^{2}=596.803 ;$ dan $\Sigma X Y$ adalah 565.066. Untuk mengetahui koefisien korelasi, maka nilai-nilai tersebut dimasukan dalam rumus koefisien korelasi dengan perolehan adalah 0.267, karena nilainya positif, maka hubungan antara pembelajaran berbasis masalah dengan literasi lingkungan bersifat linier positif dan searah walapun lemah, artinya peningkatan perolehan dalam pelaksanaan pembelajaran berbasis masalah akan diikuti dengan peningkatan literasi lingkungan siswa.

Berikut ini disajikan hubungan antara pembelajaran berbasis masalah dan literasi lingkungan siswa dengan persamaan regresi y $=0,1872+87,989$ dengan hasil perhitungan nilai koefisien determinasi $\left(\mathrm{R}^{2}\right)$ adalah 0,0713, artinya penerapan pembelajaran berbasis masalah memberikan kontribusi sebesar $7,1 \%$ terhadap literasi lingkungan. Sisanya sebesar 92,9\% merupakan konstribusi dari variaabel-variabel lain.

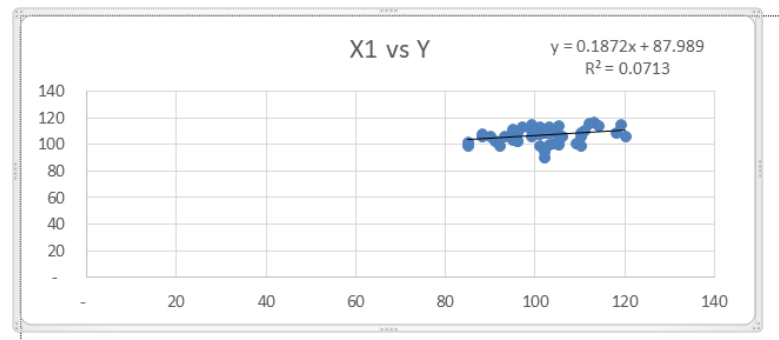

Gambar 1. Hubungan antara penerapan PBM dengan literasi lingkungan

$$
\text { Korelasi antara penerapan }
$$
pmbelajaran berbasis masalah (X1) dengan 
literasi lingkungan siswa mempunyai hubungan sebesar 7,1\%. Hubungan X1 dengan $\mathrm{Y}$ bersifat linier positif, karena setiap nilai X1 meningkat, maka dapat diprediksi akan semakin meningkatkan nilai Y (perfect coeficien), karena titik-titik pada diagram pancar mendekati bentuk garis lurus, karena itu jika X1 naik maka Y juga akan naik.

Data hasil penelitian hubungan antara keterampilan berpikir kritis dan literasi lingkungan, secara ringkas dapat ditampilkan pada tabel 2 berikut ini.

Tabel 2. Hubungan antara keterampilan berpikir kritis dengan literasi lingkungan

\begin{tabular}{|c|c|c|c|c|c|}
\hline Jumlah siswa & $\mathrm{X} 2$ & Y & $X 2^{2}$ & $\mathrm{Y}^{2}$ & $\mathrm{X} 2 \mathrm{Y}$ \\
\hline 56 & 5.337 & 5.563 & 555.487 & 596.803 & 572.072 \\
\hline
\end{tabular}

Berdasarkan Tabel 2 di atas diperoleh bahwa nilai $\Sigma X 2$ adalah $5.337 ; \Sigma Y=5.563$; $\Sigma X 2^{2}=555.487 ; \Sigma \mathrm{Y}^{2}=5965.803 ;$ dan $\Sigma \mathrm{X} 2 \mathrm{Y}$ adalah 572.072. Untuk mengetahui koefisien korelasi, maka nilai-nilai tersebut dimasuka dalam rumus koefisien korelasi dengan perolehan adalah 0.311, karena nilainya positif, maka hubungan antara keterampilan berpikir kritis dan literasi lingkungan siswa bersifat linier positif dan searah walaupun lemah, artinya peningkatan perolehan tingkat keterampilan berpikir kritis siswa akan diikuti dengan peningkatan kemampuan literasi lingkungan siswa.

Berikut ini disajikan hubungan antara keterampilan berpikir kritis dan literasi lingkungan dengan persamaan regresi $\mathrm{y}=$ $0,1444+92,16$ dengan hasil perhitungan nilai koefisien determinasi $\left(\mathrm{R}^{2}\right)$ adalah $9,7 \% \%$, artinya tingkat keterampilan berpikir kritis siswa memberikan kontribusi sebesar 9,7\% terhadap literasi lingkungan. Sisanya sebesar 90,3\% merupakan konstribusi dari variaabelvariabel lain. Hubungan X2 dengan $\mathrm{Y}$ bersifat linier pisitif, karena titik-titik pada diagram pancar mendekati bentuk garis lurus, karena itu jika X2 naik maka Y juga akan naik.

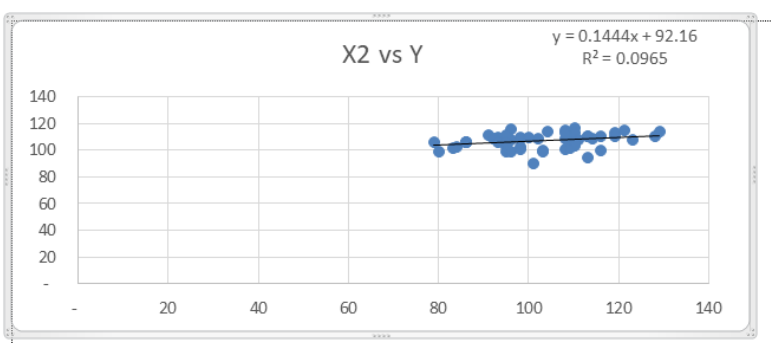

Gambar 2. Hubungan penerapan keterampilan berpikir kritis dengan literasi lingkungan

Korelasi antara penerapan keterampilan berpikir kritis (X2) dengan literasi lingkungan siswa (Y) mempunyai hubungan sebesar 7,1\%. Hubungan X1 dengan $\mathrm{Y}$ bersifat linier positif, karena setiap nilai X1 meningkat, maka dapat diprediksi akan semakin meningkatkan nilai $\mathrm{Y}$ (perfect coeficien), karena itu jika $\mathrm{X} 1$ naik maka $\mathrm{Y}$ juga akan naik.

Data hasil penelitian hubungan antara penerapan pembelajaran berbasis masalah dengan keterampilan berpikir kritis, secara ringkas dapat ditampilkan pada tabel 3 berikut ini.

Tabel 3. Hubungan pembelajaran berbasis masalah dengan keterampilan berpikir

\begin{tabular}{|c|c|c|c|c|c|}
\hline Jumlah siswa & $\mathrm{Xl}$ & $\mathrm{X} 2$ & $\mathrm{Xl}^{2}$ & $X 2^{2}$ & XIX2 \\
\hline 56 & 5.276 & 5.337 & 538.706 & 555.487 & 543.695 \\
\hline
\end{tabular}

Berdasarkan Tabel 3 di atas diperoleh bahwa nilai $\Sigma$ X1 adalah 5.276; $\Sigma$ X2 $=5.337$; $\Sigma X 1^{2}=538.706 ; \Sigma X 2^{2}=555.487 ;$ dan $\Sigma$ X1X2 adalah 543.695. Untuk mengetahui koefisien korelasi, maka nilai-nilai tersebut dimasuka dalam rumus koefisien korelasi dengan perolehan adalah 0.429, karena nilainya positif, maka hubungan antara penerapan pembelajaran berbasis masalah dan keterampilan berpikir kritis bersifat linier positif dan searah, artinya peningkatan perolehan dalam pembelajaran berbasis masalah akan diikuti dengan peningkatan keterampilan berpikir kritis siswa.

Berikut ini disajikan hubungan antara pembelajaran berbasis masalah dan keterampilan berpikir kritis dengan persamaan regresi $\mathrm{y}=0,2841+72,30$ dengan hasil perhitungan nilai koefisien determinasi $\left(\mathrm{R}^{2}\right)$ adalah $18,4 \% \%$, artinya penerapan pembelajaran berbasis masalah memberikan kontribusi sebesar $18,4 \%$ terhadap 
keterampilan berpikir kritis siswa. Sisanya sebesar 81,6\% merupakan konstribusi dari variaabel-variabel lain. Hubungan X1 dengan $\mathrm{X} 2$ bersifat linier pisitif, karena titik-titik pada diagram pancar mendekati bentuk garis lurus, karena itu jika X1 naik maka X2 juga akan naik.

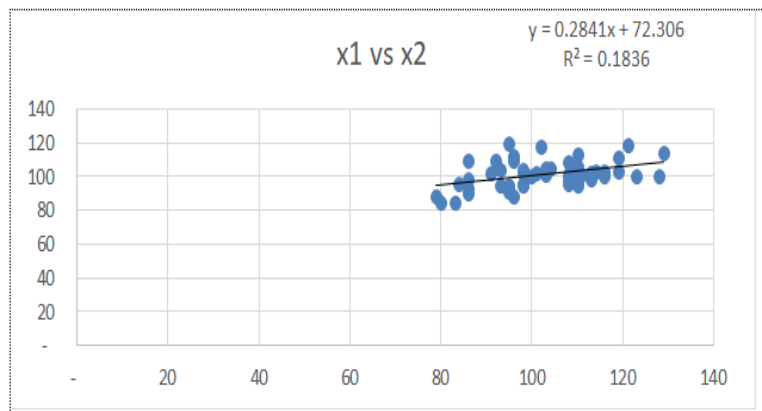

Gambar 3. Hubungan penerapan PBM dengan literasi lingkungan

Data hasil penelitian hubungan pembelajaran berbasis masalah dan keterampilan berpikir kritis siswa dengan literasi lingkungan ditampilkan seperti pada tabel 4 berikut.

Tabel 4. Hubungan PBM dan keterampilan berpikir kritis siswa dengan literasi lingkungan

\begin{tabular}{|cccccccccccc|}
\hline $\begin{array}{c}\text { Jumlah } \\
\text { siswa }\end{array}$ & $\mathrm{X} 1$ & $\mathrm{X} 2$ & $\mathrm{Y}$ & $\mathrm{X}^{2}$ & $\mathrm{X}^{2}$ & $\mathrm{Y}^{2}$ & $\mathrm{X} 1 \mathrm{Y}$ & $\mathrm{X} 2 \mathrm{Y}$ & $\mathrm{X} 1 \mathrm{X} 2$ \\
\hline 56 & 5.276 & 5.337 & 5.563 & 538.706 & 555.487 & 596.803 & 565.066 & 572.072 & 543.695 \\
\hline
\end{tabular}

Berdasarkan Tabel.4 di atas diperoleh bahwa nilai $\Sigma$ X1 adalah 5.276; $\Sigma$ X2 = 5.337; $\Sigma \mathrm{Y}=5.563 ; \Sigma \mathrm{X} 1^{2}=538.706 ; \Sigma \mathrm{X} 2^{2}=$ $555.487 ; \Sigma Y^{2}=596.803 ; \Sigma X 1 Y=565.066$; $\Sigma X 2 Y=572.072$ dan $\Sigma X 1 X 2$ adalah 543.695. Untuk mengetahui koefisien korelasi, maka nilai-nilai tersebut dimasuka dalam rumus koefisien korelasi dengan perolehan adalah 0.337 , karena nilainya positif, maka hubungan antara hubungan pembelajaran berbasis masalah dan keterampilan berpikir kritis siswa dengan literasi lingkungan bersifat linier positif dan searah, artinya peningkatan perolehan dalam hubungan pembelajaran berbasis masalah dan keterampilan berpikir kritis siswa akan diikuti dengan kemampuan literasi lingkungan siswa.

Berikut ini disajikan hubungan antara hubungan pembelajaran berbasis masalah dan keterampilan berpikir kritis siswa dengan persamaan regresi $\mathrm{y}=0,5473+45,49$ dengan hasil perhitungan nilai koefisien determinasi $\left(\mathrm{R}^{2}\right)$ adalah $11,3 \%$, artinya tingkat hubungan pembelajaran berbasis masalah dan keterampilan berpikir kritis siswa memberikan kontribusi sebesar $11,3 \%$ terhadap literasi lingkungan. Sisanya sebesar $88,7 \%$ merupakan konstribusi dari variaabelvariabel lain.

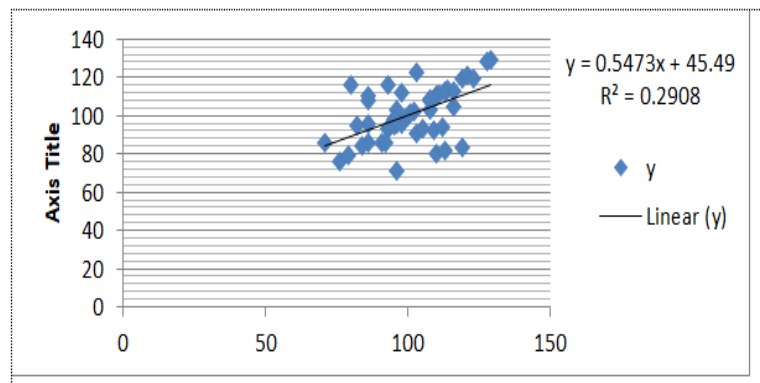

Gambar 4. Hubungan PBM dan keterampilan berpikir kritis dengan literasi lingkungan

Hubungan X1 dan X2 dengan $\mathrm{Y}$ bersifat linier positif, karena titik-titik pada diagram pancar mendekati bentuk garis lurus, karena itu jika X1 naik maka X2 juga akan dikuti dengan Y naik.

Sebagai sebuah konsep yang sedang berkembang, literasi lingkungan merupakan bagian yang tidak terpisahkan dari pendidikan lingkungan (Srbinovski, Erdogan, \& Ismaili, 2010). Dalam beberapa tahun terakhir, literasi lingkungan telah dianggap sebagai komponen yang paling penting pendidikan lingkungan (Saribas, Teksoz, \& Ertepinar, 2014). Hasil analisis data dengan menggunakan korelasi parsial adalah bahwa pembelajaran berbasis masalah berpengaruh positif dan signifikan terhadap literasi lingkungan yang dibuktikan dengan koefisien korelasi perolehan sebesar 0.267 (positif). Melestarikan lingkungan hidup merupakan salah satu kewajiban sekaligus tanggungjawab bagi setiap masyarakat lebih-lebih bagi para siswa-siswi di sekolah atau madrasah. Setiap orang harus melakukan kegiatan yang serius dan sungguhsungguh untuk menyelamatkan lingkungan hidup di sekitar kita sesuai dengan kemampuan dan kapasitasnya masing-masing. Sekecil apa pun upaya yang kita lakukan sangat besar manfaatnya untuk terwujudnya bumi yang layak huni bagi generasi yang akan datang.

Untuk mengatasi masalah yang 
berkaitan dengan berbagai permasalahan lingkungan dibutuhkan keterampilan untuk berpikir, yakni berpikir kritis agar permasalahan lingkungan dapat diatasi secara menyeluruh. Keterampilan berpikir kritis diperlukan untuk mengatasi masalah kehidupan sehari-hari (Putra, Prayitno, \& Mariadi, 2018). Keterampilan berpikir adalah kompetensi utama untuk menyelesaikan masalah, seperti permasalahan nyata dalam kehidupan (Puspitawati et al., 2018). Berpikir kritis menjadi sangat penting karena masalah nyata dalam kehidupan saat ini semakin kompleks (Mutakinati, Anwari, \& Yoshisuke, 2018).

Siswa yang memiliki kemampuan berpikir kritis sangat memperhatikan berbagai fenomena alam yang berkaitan dengan pelestarian lingkungan hidup antara lain, seperti terjadinya bencana tanah longsor dan banjir menunjukkan peristiwa yang berkaitan dengan masalah tanah. Upaya pelestarian tanah dapat dilakukan dengan cara menggalakkan kegiatan menanam pohon atau penghijauan kembali (reboisasi) terhadap tanah yang semula gundul. Untuk daerah perbukitan atau pegunungan yang posisi tanahnya miring perlu dibangun terasering atau sengkedan, sehingga mampu menghambat laju aliran air hujan.

Termasuk juga memiliki kepedulian terhadap hal-hal berikut ini, seperti 1) pelestarian Hutan, eksploitasi hutan yang terus menerus berlangsung sejak dahulu hingga kini tanpa diimbangi dengan penanaman kembali, menyebabkan kawasan hutan menjadi rusak. 2) Pelestarian flora dan fauna, kehidupan di bumi merupakan sistem ketergantungan antara manusia, hewan, tumbuhan, dan alam sekitarnya. Terputusnya salah satu mata rantai dari sistem tersebut akan mengakibatkan gangguan dalam kehidupan.3) Pelestarian laut dan pantai, seperti halnya hutan, laut juga sebagai sumber daya alam potensial. Kerusakan biota laut dan pantai banyak disebabkan karena ulah manusia. Pengambilan pasir pantai, karang di laut, pengrusakan hutan bakau, merupakan kegatan-kegiatan manusia yang mengancam kelestarian laut dan pantai
Demikian pula halnya dengan pelestarian udara, udara merupakan unsur vital bagi kehidupan, karena setiap organisme bernapas memerlukan udara. Udara terkandung beranekaragam gas, salah satunya oksigen. Udara yang kotor karena debu atau pun asap sisa pembakaran menyebabkan kadar oksigen berkurang. Keadaan ini sangat membahayakan bagi kelangsungan hidup setiap organisme. Maka perlu diupayakan kiat-kiat untuk menjaga kesegaran udara lingkungan agar tetap bersih, segar, dan sehat.

Dalam pembelajaran berbasis masalah, para siswa bekerja bersama dalam kelompok untuk mencari sekaligus memecahkan masalah dan membuat keputusan (Haji A.G, Safriana, \& Safitri R., 2015). Pembelajaran berbasis masalah adalah model yang mengutamakan kesesuaian pembelajaran dengan hal-hal yang ditemukan dalam kehidupan sehari-hari peserta didik (Nuswowati et al., 2017). Hal ini sejalan dengan pemberlakuan Kurikulum 2013 yang merekomendasikan pembelajaran dilakukan dengan pendekatan saintifik melalui metode PBM. Pembelajaran berbasis masalah mampu meningkatkan dan mengembangkan pengetahuan, kompetensi, pemecahan masalah dan keterampilan komunikasi (Delaney, Pattinson, Mccarthy, \& Beecham, 2017).

Menanamkan pengetahuan dan meningkatkan kecerdasan siswa umumnya dilakukan di sekolah/madrasah melalui pendekatan yang tepat dan efektif. Salah satu model pembelajaran yang menekankan pada kemampuan siswa untuk menyelesaikan berbagai masalah terutama masalah lingkungan adalah pembelajaran berbasis masalah. Hasil pembelajarannya dapat meningkatkan kepekaan dan kepedulian masalah lingkungan, memanfaatkan sumber daya secara bijaksana agar tidak mudah terjadinya kepunahan serta mempunyai perhatian yang besar tentang isu-isu lingkungan global.

Peningkatkan literasi lingkungan siswa melalui pembelajaran akan mengasah dan mempertajam kepekaan dan kepedulian tentang flora dan fauna yang ada di bumi ini, mempunyai perhatian yang besar terhadap 
keselamatan lingkungan, memanfaatkan sumber daya secara bijaksana agar tidak mudah terjadinya kepunahan serta mempunyai perhatian yang besar tentang isuisu lingkungan global. Semua itu akan bermuara pada terciptanya pembangunan berkelanjuan yang menitikberatkan pada pembangunan dan kemajuan teknologi dan ekonomi, namun tidak mengesampingkan kepentingan lingkungan alam dan sosial. Oleh karena itu, pembangunan berkelanjutan mencakup tiga lingkup kebijakan: pembangunan ekonomi, pembangunan sosial dan perlindungan lingkungan.

Pembelajaran berbasis masalah menuntut siswa menyusun pengetahuan secara mandiri ataupun kerjasama dalam kelompok untuk mencari penyelesaian nyata dari suatu masalah. Permasalahan yang bersifat kompleks, kontekstual dan illstructure akan memberi kesempatan kepada siswa untuk mengembangkan kemampuan berpikir analitik, evaluatif, dan reflektif dan mengembangkan kreativitasnya dalam menggali berbagai informasi, mengembangkan berbagai solusi yang mungkin, dan mengkreasi berbagai sumber guna memecahkan masalah yang harus dipecahkan (Tsai \& Chiang, 2013). Pembelajaran berbasis masalah meningkatkan kepercayaan diri pelajar, menyediakan lingkungan yang mendukung yang mendorong kerja tim, meningkatkan komunikasi interpersonal dan keterampilan memecahkan masalah, dan mendorong kesadaran diri (Moody, Mchugh, Baker, Santizo, \& Schechter, 2018; Aldarmahi, 2016).

\section{KESIMPULAN}

Berdasarkan hasil penelitian dan pembahasan mengenai hubungan pembelajaran berbasis masalah dan keterampilan berpikir kritis dengan literasi lingkungan, maka dapat disimpulkan sebagai berikut:

1. Pembelajaran berbasis masalah berpengaruh positif dan signifikan terhadap literasi lingkungan yang dibuktikan dengan koefisien korelasi perolehan sebesar 0.267 (positif).
2. Keterampilan berpikir kritis berpengaruh positif dan signifikan terhadap literasi lingkungan yang dibuktikan dengan koefisien korelasi perolehan sebesar 0.311 (positif).

3. Pembelajaran berbasis masalah berpengaruh positif dan signifikan terhadap keterampilan berpikir kritis siswa yang dibuktikan dengan koefisien korelasi perolehan sebesar 0.429 (positif).

4. Pembelajaran berbasis masalah dan keterampilan berpikir kritis siswa berpengaruh positif terhadap literasi lingkungan yang dibuktikan dengan koefisien korelasi perolehan sebesar 0.337 (positif).

\section{DAFTAR PUSTAKA}

Aljaafil, E., \& Şahin, M. (2019). Critical thinking skills for primary education: the case in Lebanon. Turquoise International Journal of Educational Research and Social Studies Turquoise International Journal of Educational Research and Social Studies ISSN:, 1(1), 1-7.

Anazifa, R. . and, \& Djukri. (2017). ProjectBased Learning and Problem- Based Learning : are They Effective to Improve Student ' S Thinking Skills. Jurnal Pendidikan IPA Indonesia, 6(2), 346355.

Astuti, A. ., Aziz, A., Sumarti, S. ., \& Bharati, D. A. . (2019). Preparing 21st century teachers: implementation of $4 \mathrm{C}$ character's pre-service teacher through teaching practice preparing 21 st century teachers: implementation of $4 \mathrm{c}$ character's pre-service teacher through teaching practice. Journal of Physics: Conference Series, 1233, 1-8.

Bedir, H. (2019). Pre-service ELT teachers' beliefs and perceptions on 21st century learning and innovation skills (4Cs). Journal of Language and Linguistic Studies, 15(1), 231-246.

Bustami, Y., Syafruddin, D., \& Afriani, R. (2018). The implementation of contextual learning to enhance biology students ' critical thinking skills. Jurnal Pendidikan IPA Indonesia, 7(4), 451457.

Dewi, I. P. M., Suryadarma, I. G. P., 
Wilujeng, I., \& Wahyuningsih, S. (2017). The effect of science learning integrated with local potential of wood carving and pottery towards the junior high school students ' critical thinking skills. Jurnal Pendidikan IPA Indonesia, 6(1), 103-109.

Karimzadegan, H., \& Meiboudi, H. (2012). Exploration of environmental literacy in science education curriculum in primary schools in Iran. Procedia - Social and Behavioral Sciences, 46, 404-409.

Khasanah, A. N., Sajidan, \& Widoretno, S. (2017). Effectiveness of critical thinking indicator-based module in empowering student' s learning outcome in. Jurnal Pendidikan IPA Indonesia, 6(1), 187195.

Kurniawan, E., Muslim, S., Rahmadyanti, E., Aribowo, W., Kusumawati, N., Ismayati, E., \& Basuki, I. (2019). Vocational students readiness in the face of the Industrial Revolution 4.0 and the demands of life in the 21st Century Skills. Celebes Education Review, 1(1), 40-52.

Machin, A. (2014). Implementasi pendekatan saintifik, penanaman karakter dan konservasi pada pembelajaran materi pertumbuhan. Jurnal Pendidikan IPA Indonesia, 3(1), 28-35.

Martini, Rosdiana, L., Subekti, H., \& Setiawan, B. (2018). Strengthening students' characters and ecopreneurship through science, environment, technology, and society course. Jurnal Pendidikan IPA Indonesia, 7(2), 162171.

Mutakinati, L., Anwari, I., \& Yoshisuke, K. (2018). Analysis Of Students' Critical Thinking Skill of Middle School Through STEM Education Project-Based Learning. Jurnal Pendidikan IPA Indonesia, 7(1), 54-65.

Nuswowati, M., Susilaningsih, E., Ramlawati, \& Kadarwati, S. (2017). Implementation of problem-based learning with green chemistry vision to improve creative thinking skill and students, creative actions. Jurnal Pendidikan IPA Indonesia, 6(2), 221-228.
Puspitawati, R. P., Yuanita, L., Rahayu, Y. S., Indana, S., \& Susiyawati, E. (2018). Two problem solving cycles to achieve learning outcomes of thinking skills and plant anatomy concept mastery. Jurnal Pendidikan IPA Indonesia, 7(3), 312321.

Putra, B. K. B., Prayitno, B. A., \& Mariadi. (2018). The effectiveness of guided inquiry and instad towards students , critical thinking skills on circulatory system materials. Jurnal Pendidikan IPA Indonesia, 7(4), 476-482.

Rochmawati, A., Wiyanto, \& Ridlo, S. (2019). Analysis of 21 st Century Skills of Student on Implementation Project Based Learning and Problem Posing Models in Science Learning. Journal of Primary Education, 9(1), 58-67.

Sada, C. (2019). Exploring t eaching learning $\mathrm{p}$ rocess in developing higher order thinking skill (HOT) to higher secondary school ( SMA) students in Pontianak. Journal of Education, Teaching, and Learning, 4(1), 228-232.

Saribas, D., Teksoz, G., \& Ertepinar, H. (2014). The relationship between environmental literacy and self-efficacy beliefs toward environmental education. Procedia - Social and Behavioral Sciences, 116, 3664-3668.

Srbinovski, M., Erdogan, M., \& Ismaili, M. (2010). Environmental literacy in the science education curriculum in Macedonia and Turkey. Procedia Social and Behavioral Sciences, 2(2), 45284532.

Suciati, Ali, M. N., Imaningtyas, C. D., Anggraini, A. F., \& Dermawan, Z. (2018). The profile of XI grade students ' scientific thinking abilities on scientific approach implementation. Jurnal Pendidikan IPA Indonesia, 7(3), 341346.

Suwono, H., Pratiwi, H. ., Susanto, H., \& Susilo, H. (2017). Enhancement of student' biological literacy and critical thinking of biology through sociobiological. Jurnal Pendidikan IPA Indonesia, 6(2).

Widowati, A., Anjarsari, P., Rahardjo, S. B., 
\& Elfi, V. H. (2017). The Development of Scientific Literacy through Nature of Science ( NoS ) within Inquiry Based Learning Approach The Development of Scientific Literacy through Nature of Science ( NoS ) within Inquiry Based Learning Approach. Journal of Physics: Conference Series, 909, 1-7. 